OPEN $\%$ ACCESS Freely available online

http://www.banglajol.info/index.php/BJID/index

Case Report

Bangladesh Journal of Infectious Diseases

June 2014, Volume 1, Number 1

ISSN (online) 2411-670X

ISSN (Print) 2411-4820

\title{
Concomitant Dengue Fever with Haemophilus influenza and Candida tropicalis in an Infant: A Rare Association
}

\author{
Jagdish Kathwate ${ }^{1}$, Ira Shah $^{2}$
}

${ }^{1}$ Registrar, Bai Jerbai Wadia Hospital for Children, Mumbai-400036,India; ${ }^{2}$ Incharge, Pediatric HIV and TB Clinic \& Associate Professor of Pediatrics, Bai Jerbai Wadia Hospital for Children, Mumbai \& Consultant in Pediatric Infectious Diseases, Nanavati Hospital, Mumbai, India

[Received: 1 January 2014; Accepted: 15 March 2014; Published: 1 December 2014]

\begin{abstract}
Dengue represents common endemic infection in tropical areas. Occurrence of bacterial and fungal superinfection or coinfection in patients with dengue is rare. In case of persistent fever in patients with dengue, co-infection with bacteria and fungi should be kept in mind and patients should be investigated accordingly. We report an unique case of an infant with severe dengue fever presenting as meningoencephalitis with co-infection with Hemophilus Influenza and Candida tropicalis. [Bangladesh J Infect Dis 2014;1(2):38-40]
\end{abstract}

Keywords: Dengue; co-infection; Haemophilus Influenza; Candida tropicalis

Correspondence: Jagdish Kathwate, Flat No.204, Sai Ganesh Residency „Bhumkar nagar,Narhe, pune 400401, India; Email: docjagdishkat@gmail.com

How to cite this article: Kathwate J, Shah I. Concomitant Dengue Fever with Haemophilus influenza and Candida tropicalis in an Infant: A Rare Association. Bangladesh J Infect Dis 2014;1(2):38-40

Contributions to authors: JK and IS were involved in the diagnosis and management of the case. JK reviewed literature and drafted the manuscript. IS critically reviewed the manuscript.

Competing interests: None stated

\section{Introduction}

Dengue represents one of the common endemic infection in tropical areas and it has variable clinical spectrum ranging from asymptomatic infection to life-threatening severe dengue with organ failure. Fever, arthralgia, headache, petechial spots, rash and haemorrhagic manifestations are common features with which dengue infection presents ${ }^{1}$. Occurrence of bacterial and fungal superinfection or coinfection in patients with dengue is $\operatorname{rar}^{2-6}$. We report an unique case of an infant with severe dengue fever presenting as meningoencephalitis with co-infection with Hemophilus Influenza and candida tropicalis.

\section{Case Report}

One year old male child presented with fever, projectile vomiting, altered sensorium and multiple episodes of generalized tonic-clonic seizures .On presentation child was in hypotensive shock and had neck stiffness. Complete blood count revealed white cell count normal $(6,300$ cells/cu $\mathrm{mm})$ with Polymorphs (25\%), high Lymphocytes $(75 \%)$, severe thrombocytopenia (12,000 cells/cu mm) and reduced 
hemoglobin $(7 \mathrm{mg} / \mathrm{dl})$ with packed cell volume $(\mathrm{PCV})$ of $25 \%$. Dengue NS1 antigen testing performed on day 2 of fever was positive, week later Dengue IgM was also positive. C-reactive protein was high (114 $\mathrm{mg} / \mathrm{dL}$ ). Liver function and renal function were normal. Child was shifted to IPCU and required fluid resuscitation and ionotropic support.

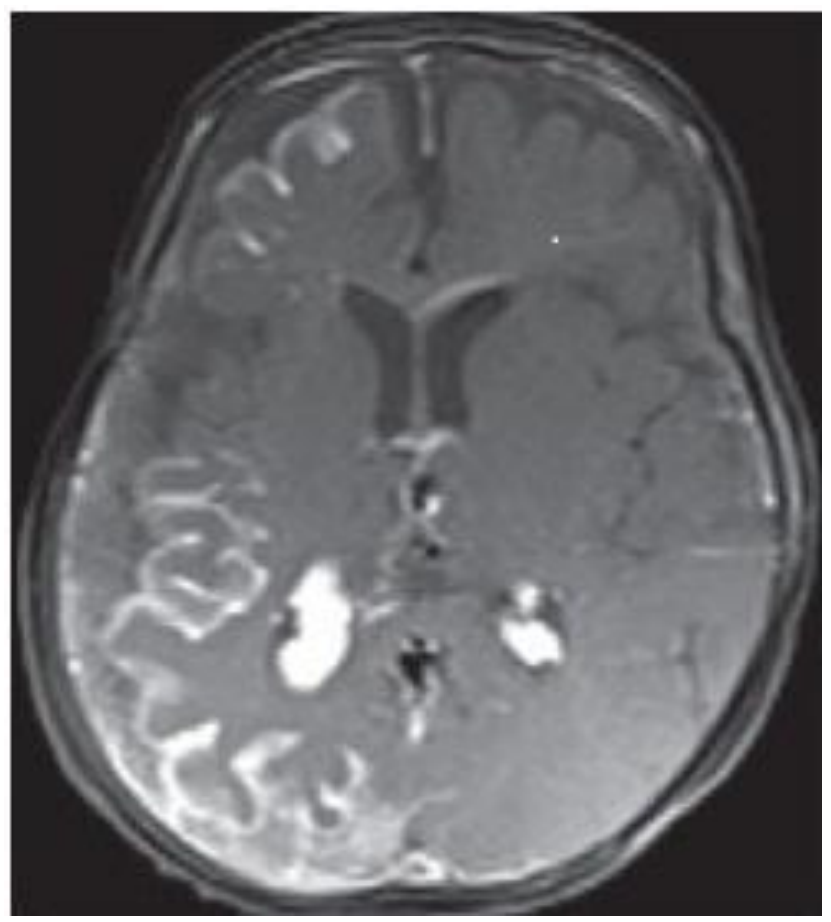

\section{Figure I: MRI of Brain}

Fever and altered sensorium were persistent; therefore, MRI brain was done that showed [Figure I] diffuse leptomeningeal enhancement, tiny focus of restricted diffusion representing non-hemorrhagic infracts in right temporal lobe and sublentiform region. On day 4 of hospitalization, lumbar puncture (LP) was performed and cerebrospinal fluid (CSF) showed raised protein $(170 \mathrm{mg} / \mathrm{dL}), 650$ cells/cu mm with high polymorphs (70\%), lymphocytes $30 \%$ and sugar $56 \mathrm{mg} / \mathrm{dl}$ with corresponding blood sugar of $95 \mathrm{mg} / \mathrm{dL}$. Gram staining of CSF did not reveal any organism but latex agglutination for $H$. Influenza was positive. Blood culture and CSF cultures did not grow any organism. The patients was started on IV ceftriaxone. Patient's sensorium improved gradually but fever continued. A CT-scan of brain was done on Day-10 of hospitalization which showed bilateral subdural empyema and mastoiditis. Mastoid fluid was aspirated and grew Candida tropicalis. Liposomal amphotericin B was added following which fever subsided. The patient was given 21 days of Ceftriaxone and total dose of $40 \mathrm{mg} / \mathrm{kg}$ of liposomal amphotericin B. The patient is now in regular follow up and is growing well.

\section{Discussion}

The occurrence of co-infection by dengue virus and bacteria has been underestimated and only few case reports have been published. Among 774 patients presenting with DHS, Lee and others observed that $5.5 \%$ of the patients had bacteraemia ${ }^{7}$. Microorganisms have been identified as occurring simultaneously with dengue virus infection include Streptococcus pneumoniae, E. coli, Salmonella species, Shigella sonnei, Klebsiella species, Enterococcus faecalis, Moraxella lacunata, Staphylococcus aureus, Haemophilus influenza, Candida tropicalis, Mycobacterium tuberculosis, Mycoplasma and herpes viruses $^{2-6}$. Similarly in this case Haemophilus influenza was detected in CSF by latex agglutination test and mastoid fluid showed Candida tropicalis.

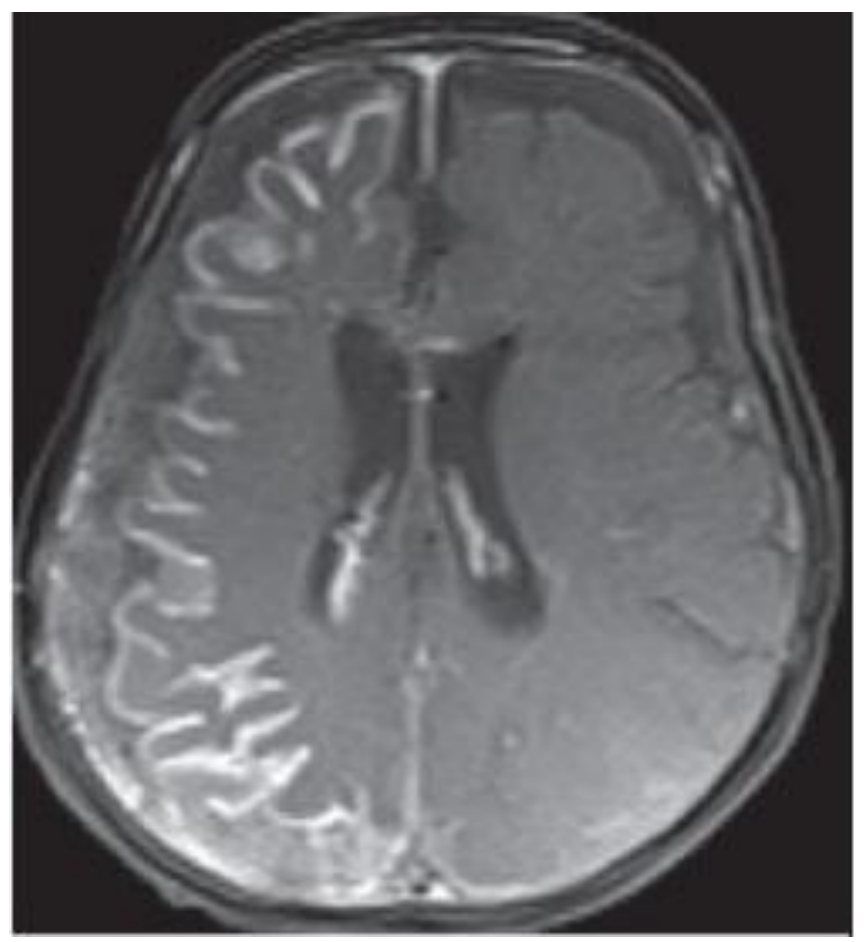

\section{Figure II: MRI of Brain}

As for the pathogens isolated from blood in bacteremic patients in case series with the exception of one isolate of Rosemonas species and another isolate of $K$. ozaenae, the majority of the bacteria like three isolates of $K$. pneumoniae, one of M. lacunata, and one of E. faecalis are normally found in the intestinal tract ${ }^{7}$. It can be assumed that most of the above mentioned bacteria invaded the bloodstream from the intestinal lumens of the patients because dengue virus infections may lead to disintegration of intestinal mucosal barrier, resulting in creation of a portal of entry for pathogens that normally inhabit the intestinal tract ${ }^{8}$. Whether this the occurrence of 
bacterial or fungal infection superimposed on the dengue virus infection is purely coincidence or more likely due immunosuppression caused by the virus needs to be further investigated ${ }^{9}$.

\section{Conclusion}

This case report permits to conclude that in case of persistent fever in patients with dengue, co-infection with bacteria and fungi should be kept in mind and patients should be investigated accordingly.

\section{References}

1. Shepard DS, Undurraga EA, Halasa YA (2013). "Economic and disease burden of dengue in Southeast Asia". PLoS Negl Trop Dis 7 (2): e2055

2. Suzuki S, Kitazawa T, Ota Y, Okugawa S, Tsukada K, Nukui Y, Hatakeyama S, Yamaguchi D Dengue hemorrhagic shock and disseminated candidiasis. Intern Med.2007;46:1043-1046
3. Kohli U, Sahu J, Lodha R, Agarwal N, Ray R. Invasive nosocomial aspergillosis associated with heart failure and complete heart block following recovery from dengue shock syndrome. Pediatr Crit Care Med. 2007;8:389-391

4. Tang Y, Kou Z, Tang X, Zhang F, Yao X, Liu S, Jin X. Unique impacts of HBV co-infection on clinical and laboratory findings in a recent dengue outbreak in China. Am J Trop Med Hyg. 2008;79:154-158

5. Thangaratham PS, Jeevan MK, Rajendran R, Samuel PP, Tyagi BK. Dual infection by dengue virus and Plasmodium vivax in Alappuzha District, Kerala, India. Jpn J Infect Dis.2006;59:211-212

6. Pancharoen C, Thisyakorn U. Coinfections in dengue patients. Pediatr Infect Dis. 1998;17:81-82

7. Lee IK, Liu JW, Yang KD. Clinical characteristics and risk factors for concurrent bacteremia in adults with dengue hemorrhage fever. Am J Trop Med Hyg. 2005;72:221-226

8. Lin CF, Lei HY, Shiau AL, Liu HS, Yeh TM, Chen SH, Liu CC, Chiu SC, Lin YS, 2002. Endothelial cell apoptosis induced by antibodies against dengue virus nonstructural protein 1 via production of nitric oxide. $J$ Immunol 169: 657-664

9. Rouse BT, Horohov DW. Immunosuppresion in viral infections. Rev Infect Dis.1986;8:850 